\title{
Perfechatividades de gênero: a contribuição das fechativas e afeminadas à teoria da
} performatividade de gênero*

\author{
Leandro Colling** \\ Murilo Souza Arruda*** \\ Murillo Nascimento Nonato****
}

\section{Resumo}

Este trabalho avalia algumas críticas relacionadas à teoria da performatividade de gênero, criada por Judith Butler, e propõe a perfechatividade para pensar a performatividade de gênero a partir de pesquisas sobre gays fechativos e/ou afeminados realizadas em Salvador. Para realizar esse percurso, o texto divide as críticas à Butler em dois blocos e explica como ela ampliou a teoria da performatividade de gênero $e$, ao mesmo tempo, respondeu aos seus críticos. Ao fazer isso, Butler qualificou a sua teoria, mas usou uma distinção entre performance e performatividade que pode ser problematizada a partir dos estudos da performance e daquilo que estamos nomeando como perfechatividade.

Palavras-chave: Performatividade de Gênero, Performance, Sexualidade, Queer.

* Recebido em 09 de outubro de 2017, aceito em 22 de abril de 2019.

** Professor permanente do Programa Multidisciplinar de Pós-graduação em Cultura e Sociedade; professor colaborador do Programa de Pós-Graduação em Estudos Interdisciplinares sobre Mulheres, Gênero e Feminismo, da Universidade Federal da Bahia; coordenador do Núcleo de Pesquisa e Extensão em Culturas, Gêneros e Sexualidades (NuCuS), Salvador, Brasil. leandro.colling@gmail.com / 0000-0002-0519-2991

*** Professor assistente da Faculdade de Direito da Universidade Católica de Salvador (UCSal); professor substituto da Área de Antropologia da Universidade Estadual de Feira de Santana (UEFS), Feira de Santana, BA, Brasil. Também é coordenador do Núcleo de Análise em Direitos Humanos e Alteridades (NADHAUCSAL). murilosarruda@gmail.com / 0000-0002-4947-7438

**** Mestre pelo Programa Multidisciplinar de Pós-graduação em Cultura e Sociedade, Salvador, Bahia, Brasil. nonato.murillo@gmail.com / 0000-00034974-5444 


\begin{abstract}
The paper evaluates some critiques related to the gender performativity theory, created by Judith Butler, and proposes the perfechatividade to think about the gender performativity by means of researches about flamboyant / or effeminate gays performed in Salvador. To accomplish this, the text divides the criticism to Butler into two blocks and explains how she expanded the gender performativity theory and, at the same time, responded to its critics. By doing so, Butler improved her theory but used a distinction between performance and performativity that can be problematized through performance studies and through what we are naming as perfechatividade.
\end{abstract}

Keywords: Gender Performativity, Performance, Sexuality, Queer. 


\section{Performatividade $e$ a materialidade dos corpos}

Este texto explica, inicialmente, como Judith Butler desenvolveu e revisou a sua teoria da performatividade de gênero, $e$ analisa algumas críticas que a autora recebeu ao longo das últimas três décadas. Esse esforço, em seguida, será importante para propormos a perfechatividade para pensar a performatividade de gênero de gays fechativos e/ou afeminados. Essa proposição foi criada a partir de pesquisas realizadas em Salvador, que evidenciaram a dificuldade de distinguir performance e performatividade de gênero, distinção presente em alguns textos de Butler.

A teoria da performatividade de gênero começou a ser desenvolvida por Judith Butler no final do seu livro Problemas de gênero, cuja primeira edição, em língua inglesa, é de 1990. Nesses 29 anos, a autora revisou e ampliou sua teoria e, como ela mesmo destaca, isso ocorreu em função das críticas realizadas por uma série de pessoas relacionadas com os estudos de gênero $e$ sexualidade e/ou do ativismo. ${ }^{1}$

${ }^{1}$ Não faremos aqui uma revisão detalhada de todas as críticas que Butler recebeu desde a publicação de Problemas de gênero. Esse esforço já foi realizado por algumas pessoas. Destacamos, por exemplo, os trabalhos de Patrícia SoleyBeltran e Leticia Sabsay (2012), que organizaram o livro Judith Butler en disputa - lecturas sobre la performatividad, e a obra de Pablo Pérez Navarro (2008), Del texto ao sexo - Judith Butler y la performatividad. Nesse livro, Navarro produz uma genealogia da teoria da performatividade, na qual explica as influências teóricas que levaram Butler a produzir sua teoria, e também analisa algumas críticas realizadas por feministas como Nancy Fraser (ver Butler, 2016, e Fraser, 2017). No livro organizado por Soley-Beltran e Sabsay há outro texto em que Navarro (2012) avalia as críticas de Martha Nussbaum e Celia Amorós à Butler. Quem acompanha os debates sobre os impactos dos estudos queer no feminismo $e$ ativismo feminista e LGBT não se surpreenderá com as críticas realizadas por essas autoras, que alegam, ao nosso ver equivocadamente, que o pensamento de Butler trata de questões "meramente culturais" ou de que não oferece uma saída sobre como resistir em escala macro frente aos preconceitos de gênero $e$ sexualidade. Nussbaum, em tom desrespeitoso, chegou a dizer que o pensamento de Butler promove um "quietismo modernoso conivente com o mal" (Salih, 2012:202). Sobre esse debate, ver o último capítulo de Sara Salih (2012), que destaca como Gayatri Spivak respondeu ao texto de Nussbaum, em defesa 
Em um bloco de críticas à teoria da performatividade, poderíamos reunir pessoas que enfatizam que a materialidade do corpo parece ter sido esquecida ou negligenciada por Butler. Paul B. Preciado fez isso em pelo menos três momentos. Em Manifiesto contra-sexual, de 2004 e traduzido para a língua portuguesa em 2014, obra em que analisa os dildos (conhecidos no Brasil como "consolos"), disse que o gênero não é simplesmente performativo como quer, na leitura de Preciado, Butler.

O gênero é antes de tudo prostético, quer dizer, não se dá senão na materialidade dos corpos. É puramente construído e ao mesmo tempo inteiramente orgânico [...]. O gênero se parece ao dildo. Porque os dois passam da imitação (Preciado, 2002:25).

No texto Cuerpo y discurso en la obra de Judith Butler: políticas de lo abyecto, publicado em 2005, ele diz que Butler

tem utilizado a figura da drag queen para explicar a construção do gênero como performance. Para Butler, a drag queen é uma figura de subversão da identidade porque faz uma explícita construção performativa do gênero (Preciado, 2005:128).

de Butler. Essa crítica de que os estudos queer só servem para fazer crítica cultural também apareceu em vários outros momentos no Brasil, a exemplo da conferência de encerramento do $9^{\circ}$ Fazendo Gênero, de 2010, proferida por Miguel Vale de Almeida. Para saber mais sobre isso e para verificar como os estudos queer impactam $e$ incentivam novas formas de fazer política sexual e de gênero, ver Colling (2015). Críticas mais sólidas e respeitosas à obra de Butler podem ser encontradas no livro de María Luisa Femenías (2003), intitulado Judith Butler: introducción a su lectura. Outro texto que analisa críticas realizadas ao pensamento de Butler, com destaque para as produzidas por Seyla Benhabib, foi escrito por Ingrid Cyfer (2015) e publicado na revista Lua Nova. Mais recentemente, outras pesquisadoras também têm dialogado criticamente com a teoria da performatividade através de outras influências. Barad (2017), por exemplo, defende que a teoria de Butler é antropocêntrica porque não leva em consideração a performatividade da matéria. Além do gênero ser performativo, a matéria de humanos e não humanos também o é, defende Barad. 
Logo em seguida, depois de tratar de como Monique Wittig descreve determinada prática sexual entre lésbicas, nomeada por bollo-lobo, sentencia:

No sexo bollo-lobo descrito por Wittig, não há performance ao estilo Butler. Não há repetição nem imitação do sexo heterossexual. De fato, o processo descrito por Wittig não é da ordem da imitação, mas do que Deleuze e Guattari chamaram de "devir" (...) Quando oponho aqui a noção de "devir" a da "performance", não trato de negar a dimensão "performativa" no processo de formação identitária. Não trato de negar a força da linguagem para produzir a realidade, mas essa força performativa não pertence a ordem de uma enunciação individual e voluntária ou inclusive voluntarista, mas sim a ordem da promessa, a maldição ou o sortilégio, de um pacto sempre político em que nos jogamos com o corpo (Preciado, 2005:129). ${ }^{2}$

Em Testo yonqui, de 2008, volta a questionar a teoria de Butler através do seu estudo sobre o uso de hormônios e o poder da "farmacologia" sobre os nossos corpos. Depois de explicar o que seria a performatividade em Butler, Preciado escreve:

O gênero (feminilidade/masculinidade) não é nem um conceito, nem uma ideologia, nem uma performance: se trata de uma ecologia política. A certeza de ser homem ou mulher é uma ficção somaticopolítica produzida por um conjunto de tecnologias de domesticação do corpo, por um conjunto de técnicas farmacológicas e audiovisuais que fixam e delemitam nossas potencialidades somáticas funcionando como filtros que produzem distorções permanentes na realidade que nos rodeia (Preciado, 2008:89, grifo do autor).

Como ficará evidente ao longo do texto, Preciado não leva em consideração como Butler distingue performance da

2 Todas as traduções existentes neste texto foram realizadas pelos autores. 
performatividade, o que outras pessoas também fizeram, e usa uma prática sexual como crítica à teoria, quando a autora americana estava, nesse momento, teorizando identidade de gênero. Preciado também parece retirar a dimensão do movimento corporal que Butler preserva ao pensar performatividade de gênero. Em Butler, tal teoria não trata só da linguagem, mas também como operam as forças estruturadas $e$ estruturantes que incidem sobre a introjeção de valores que motivam a ação performativa. Butler também quer refletir sobre o movimento do corpo que tais forças ensejam e o efeito da repetição no processo de fabricação da materialidade corporal. Sua noção de performatividade encontra, numa analítica da linguagem, a gramática matricional para entender como o corpo em movimento apreende normas e emerge como projeto normativo cultural de sexo/gênero/desejo/prática sexual.

Preciado também se filia ao segundo bloco de críticas, que desenvolveremos a seguir, que reúne quem critica a teoria da performatividade por presumir um aspecto voluntarista ao gênero. Mas no caso dessas críticas feitas por Preciado, o que nos chama mais atenção é o fato de que a própria Butler, três anos após a publicação de Problemas de gênero, ou seja, bem antes dos textos de Preciado citados acima, já ter respondido críticas semelhantes. Ela iniciou assim o Bodies that matter (Cuerpos que importan): "existe alguma forma de vincular a materialidade do corpo com a performatividade do gênero?" Em um novo prefácio para a tradução de Problemas de gênero em espanhol (El género em disputa), em 1999, Butler revelou que dedicou grande parte dos últimos anos para esclarecer e revisar a teoria da performatividade, que ela própria também teria modificado "em resposta às críticas excelentes" (Butler, 2007:16).

E como a autora respondeu à pergunta que abriu Cuerpos que importan? Antes de tratar sobre isso, não concordamos com a crítica de que o corpo, ou a sua materialidade, não estava contemplado já nos primeiros esboços de Butler sobre a performatividade de gênero, realizados em Problemas de gênero. Em vários momentos desse livro, ela frisou que o resultado da 
performatividade passa a se inscrever "na superfície do corpo", de que o corpo passa a ser "marcado pelo performativo" (Butler, 2003:194). No entanto, é evidente que a discussão sobre a relação entre a materialidade dos corpos e a performatividade ela irá fazer com mais cuidado na obra seguinte. E o que, afinal, ela diz? Butler ataca as críticas e defende que

a performatividade deve ser compreendida não como um "ato" singular ou deliberado, mas, ao invés disso, como uma prática reiterativa e citacional pela qual o discurso produz os efeitos que ele nomeia. $\mathrm{O}$ que, eu espero, se tornará claro no que vem a seguir é que as normas regulatórias do "sexo" trabalham de uma forma performativa para constituir a materialidade dos corpos $e$, mais especificamente, para materializar o sexo do corpo, para materializar a diferença sexual a serviço da consolidação do imperativo heterossexual (Butler, 2001:154).

Butler começa então a fazer uma longa e complexa reflexão para evidenciar que materialidade dos corpos também, mas não só, é constituída de forma performativa. Entre outros aspectos, ela defende que os corpos são efeitos de uma dinâmica de poder, que a construção do sexo também opera com uma norma cultural que governa a materialidade dos corpos e que a heteronormatividade possibilita a existência de determinados corpos como humanizados e outros corpos como abjetos, aqueles que não gozam o status de sujeito. Ou seja, assim como existem gêneros ininteligíveis, que não são reconhecidos como gêneros aceitos porque não se enquadram no padrão binário com o qual opera a heteronormatividade, também existem corpos que não são dignos de existir socialmente, são corpos não "apropriadamente generificados" (Butler, 2001:161).

Butler faz uma crítica tanto às perspectivas essencialistas como às perspectivas construcionistas em relação ao corpo $e$ ao gênero. Segundo ela, esta última perspectiva trabalha com a ideia de que houve um sexo anterior ao gênero. Butler sugere repensarmos a oposição entre sexo e gênero. $\mathrm{O}$ construcionismo, 
diz ela, ou pensa que a construção age de forma determinista ou pressupóe um sujeito que faz o seu gênero. Butler contesta essas duas conclusões, pois enfatiza como existem corpos que não se conformam e que não há um "eu" que se coloca antes de ser submetido ao processo de generificação (Butler, 2001:160).

Parece-nos, no entanto, que a grande crítica que Butler faz aos construcionistas e, "por tabela", também aos seus críticos, é a seguinte: se é possível defender que o sexo é em parte construído e em parte "natural", é preciso traçar a linha entre o que é e o que não é construído. Onde começa a natureza e termina a incidência da cultura sobre o corpo? Para Butler, quem tentar responder questões desse tipo, ao elaborar essas "fronteiras", vai produzi-las a partir de determinadas normas.

Esse processo de distinção terá alguma força normativa $e$, de fato, alguma violência, pois ele pode se construir apenas através do apagamento; ele pode limitar uma coisa através da imposição de um certo critério, de um princípio de seletividade (Butler, 2001:165).

Em uma entrevista concedida três anos depois de Bodies that matter, Butler destaca que esse seu livro não pode ser lido como um trabalho que procura considerar a materialidade dos corpos em termos construtivistas, mas que ela busca entender que,

assim como nenhuma materialidade anterior está acessível a não ser através do discurso, também o discurso não consegue captar aquela materialidade anterior; argumentar que o corpo é um referente evasivo não equivale a dizer que ele é apenas e sempre construído. De certa forma, significa exatamente argumentar que há um limite à construtividade, um lugar, por assim dizer, onde a construção necessariamente encontra esse limite (Prins; Meijer, 2002:158).

De forma resumida e incompleta, em Cuerpos que importan Butler defende que: 1) os corpos são efeitos de uma dinâmica de 
poder; 2) a performatividade é um ato do poder reiterado do discurso; 3) a construção do sexo opera com uma norma da cultura que governa a materialidade dos corpos; 4) o "eu" que assume um sexo é formado por esse processo de assumir um sexo, que é desde sempre regulado; 5) o imperativo da heterossexualidade possibilita certas identificações sexuadas $e$ impede ou nega outras, mecanismo através do qual produz os seres considerados abjetos, aqueles que não são propriamente generificados, humanizados, que não gozam do status de sujeitos. A política feminista e queer, defende Butler, pode promover a desidentificação com essas normas regulatórias que materializam a diferença sexual (Butler, 2001:156).

Pretendemos evidenciar aqui que o esforço de Butler é criticar a perspectiva construcionista, porém sem jogar "fora o bebê com a água do banho". Para Butler, a perspectiva construcionista trabalha com a ideia de que houve um sexo anterior ao gênero e ela argumenta como esse sexo antes do gênero já faz parte de uma construção. Enfatiza também que a "natureza" não é uma superfície passiva, uma página em branco $e$ que não existe um "natural" antes da inteligibilidade.

Mas ela pergunta: se isso é verdade, afinal, o que sobra do sexo, ou melhor, da materialidade do corpo? Ele desaparece completamente? A resposta é não: "Isto não equivale a dizer que a materialidade dos corpos é simples e unicamente um efeito linguístico que possa reduzir-se a um conjunto de significantes" (Butler, 2008:57). A proposta é refletir sobre a indissolubilidade entre a materialidade e a significação, o que não é, diz ela, um assunto simples de ser tratado e estudado. E isso implica em uma série de questões que ela passa a enfrentar, tais como: como fica a "clássica associação" entre a feminilidade e o útero, a vagina e a reprodução? A vagina e o pênis não são marcas diferentes nos corpos, não dizem nada sobre a forma $e$ formação desses corpos $e$ dos seus gêneros? Como essas questões são pensadas por filósofos, feministas e psicanalistas?

A complexidade com que Butler trata dessas questões não deveria permitir aqui uma tentativa de simplificação. No entanto, 
ao ler um conjunto de textos em que ela trata dessas questões, é perceptível o quanto o seu propósito não é o de negar a materialidade dos corpos, mas de enfatizar como eles são materializados, quais as exclusões que inclusive as pessoas autoras $e$ ativistas produzem ao operar com a separação entre natureza $\mathrm{x}$ cultura, essencialismo $\mathrm{x}$ construcionismo, sexo $\mathrm{x}$ gênero, matéria/corpo x significação.

O debate entre construcionismo e o essencialismo deixa assim de perceber totalmente a desconstrução, pois o argumento nunca foi o de que 'tudo é discursivamente construído'; esse argumento, quando e onde é levado, pertence a um tipo de monismo, ou linguisticismo discursivo, de uma violenta forclusão, da abjeção e de seu retorno perturbador no interior dos próprios termos da legitimidade discursiva (Butler, 2001:162).

Ou seja, em Butler, o corpo não é resultado de eleições voluntaristas para fabricar o gênero, mas do efeito que a série de repetição iniciada na linguagem promove; as repetições promovem um efeito sobre o corpo, materializando-o expressivamente. O corpo é nutrido, a partir das repetições performáticas que corporificam, em movimento, o gênero. Dessa forma, o sujeito só é autor no processo de fabricação de seu corpo/gênero quando, vivendo, aproxima-se mais ou menos das normas que orientam as suas repetições cotidianas. $\mathrm{O}$ sujeito não é autor, mas resultado das forças culturais que o levam a se comportar mais próximo ou mais distante das normas que uma analítica da linguagem faz aparecer como códigos que modulam as repetições.

\section{Performance e performatividade: do voluntário ao involuntário}

Depois de fazer uma rigorosa reflexão teórica sobre vários estudos feministas, da psicanálise, da antropologia e da filosofia, Butler chega ao capítulo final de Problemas de gênero para defender a tese de que o gênero é performativo. Mas o que afinal 
ela quer dizer com isso? De Austin, Butler usa a conhecida tese dos atos performativos. O linguista defende que as palavras não apenas descrevem algo, mas que elas também têm o poder de criar aquilo que enunciam. Assim, quando um juiz ou sacerdote diz "eu vos declaro marido e mulher", a partir daquele momento os envolvidos passam, efetivamente, a ser aquilo que o enunciado determinou.

A mesma associação Butler faz para a frase "é menino ou é menina" proferida, atualmente, antes mesmo do parto, no momento da ultrassonografia realizada nas gestantes. ${ }^{3} \mathrm{~A}$ partir desse momento, aquele pequeno feto já passa a ter um gênero $e$ sobre ele incidem as normas de gênero construídas e impostas pela sociedade. Antes de chegar nesse momento, Butler já havia esmiuçado o mecanismo de funcionamento da heterossexualidade compulsória e da heteronormatividade, revelando como ambas se sustentam através da exigência da linha coerente entre sexogênero-desejo e prática sexual. Assim, Butler defende que, além de obrigar que todos sejamos heterossexuais (heterossexualidade compulsória) ou que, mesmo que não sejamos heterossexuais, pelo menos estejamos enquadrados nas normas tidas como heterossexuais (heteronormatividade), a sociedade também nos obriga a ter um gênero tido como compatível com a materialidade dos nossos corpos. E essas exigências, realizadas através de atos, gestos e atuações, são performativas, pois criam os sujeitos que enunciam. Para que essas ações tenham êxito é necessário que elas sejam constantemente repetidas e vigiadas.

Mas, com a influência das reflexões de poder de Foucault (onde existe poder, existe resistência/ contrapoder), e dos trabalhos de Eve Kosofsky Sedgwick, Butler destaca que nem todos e todas se sujeitam as essas normas e que esses mesmos

gêneros distintos são parte do que "humaniza" os indivíduos na sociedade contemporânea [E continua:] de fato habitualmente punimos os que não desempenham

${ }^{3}$ Sobre o assunto, ler também Chazan (2007). 
corretamente o seu gênero. Os vários atos de gênero criam a ideia de gênero, e sem esses atos, não haveria gênero algum (Butler, 2003:199).

Em Problemas de gênero, Butler analisa as performances artísticas de drags, pois enxerga nelas pelo menos três dimensões que são distintas entre si: sexo anatômico, identidade de gênero $e$ performance de gênero. Essas performances (e notem que aqui a performance, no sentido artístico, para ela, não é sinônimo de performatividade, como desenvolveremos a seguir) foram fundamentais para Butler ter a percepção da performatividade de gênero. "Ao imitar o gênero, a drag revela implicitamente a estrutura imitativa do próprio gênero - assim como sua contingência" (Butler, 2003:196).

O livro Problemas de gênero e as poucas páginas (cerca de dez) em que Butler trata da perfomatividade de gênero repercutiram além do que era esperado pela autora. Nessa repercussão, o que passou a ser chamado de teoria da performatividade de gênero recebeu muitas críticas de vários pesquisadores e ativistas. Podemos, de forma simplificada, reunir outras críticas em um bloco de quem aponta o fato de que, para essa teoria, o gênero teria aspecto voluntarista, ou seja, assim com as e os drags, qualquer pessoa poderia montar um gênero a cada dia ou até mesmo a cada hora. Trata-se, sem dúvida, de uma leitura apressada e malfeita, pois, em vários momentos, Butler destaca o quanto esse conjunto de normas constitui as nossas subjetividades.

Em outro texto, na tentativa de responder a essas e outras questões, Butler é mais explícita e diz que a performatividade de gênero não pode ser entendida sem as restrições constitutivas registradas no psiquismo e de que seria um erro associar ou reduzir o exemplo das e dos drags com a nossa performatividade de gênero diária. Para ela, a explicação voluntarista do gênero pressupõe um sujeito intacto que existe antes de assumir um gênero. 
O significado da performatividade de gênero que eu gostaria de transmitir é bastante diferente. O gênero é performativo porque é efeito de um regime que regula as diferenças de gênero. Neste regime os gêneros se dividem $e$ se hierarquizam de forma coercitiva. (..) A performatividade de gênero sexual não consiste em eleger de que gênero seremos hoje. Performatividade é reiterar ou repetir as normas mediante as quais nos constituímos: não se trata de uma fabricação radical de um sujeito sexuado genericamente. É uma repetição obrigatória de normas anteriores que constituem o sujeito, normas que não se pode descartar por vontade própria (Butler, 2002:64).

Mas o que Butler quer dizer com restrições constitutivas? Encontramos uma boa reflexão sobre essa questão no artigo Identificación fantasmática y la asunción del sexo, que integra o livro Cuerpos que importan. Continuando a responder aos críticos que interpretaram a teoria da performatividade como uma teoria voluntarista do gênero, e apontando os riscos de se defender a naturalização da sexualidade, ela reforça o argumento de que a sexualidade não é algo que podemos fazer ou desfazer ao nosso bel prazer. Isso porque somos marcados, sofremos constantemente as restrições,

que incluem o caráter radicalmente inconcebível de desejar de outro modo, o caráter radicalmente insuportável de desejar de outro modo, a ausência de certos desejos, a coação repetitiva dos demais, o repúdio permanente de algumas possibilidades sexuais, o pânico, a atração obsessiva e o nexo entre sexualidade e dor (Butler, 2008:145).

Essas restrições, diz ela, são "restrições políticas registradas psiquicamente" (Butler, 2008:144). Ou seja, não são restrições que podemos subverter facilmente.

Para responder às críticas de que a identidade de gênero em sua teoria teria um status voluntarista, Butler, em determinadas ocasiões, propôs uma diferenciação entre performance de gênero 
e performatividade de gênero. Nessa distinção, performance seria aquela realizada pelas pessoas drags e que se caracteriza por um ato limitado, produto de uma vontade ou de uma eleição de quem a realiza. "É um erro reduzir a performatividade à performance" (Butler, 2002:69). Já a performatividade de gênero, como explicamos anteriormente, não é caracterizada pela eleição ou agência do sujeito, mas pelo efeito repetido da norma, ainda que essas repetições nem sempre sejam realizadas da maneira como as normas desejam.

Não há sujeito que seja "livre" para evitar essas normas ou de examiná-las à distância. Ao contrário, essas normas constituem o sujeito de maneira retroativa, mediante a sua repetição; o sujeito é precisamente o efeito dessa repetição. O que poderíamos chamar de "capacidade de atuação", "liberdade" ou "possibilidade" é sempre uma prerrogativa política produzida pelas brechas que se abrem nessas normas reguladoras, no processo de interpelação dessas normas e em sua auto-repetição. (...) A performatividade de gênero sexual não consiste em eleger de qual gênero seremos hoje (Butler, 2002:64).

Nessa distinção entre performance e performatividade, Butler destaca que, ao pensar nas drags, estava muito mais interessada na paródia de gênero por elas produzida do que em tê-las como exemplo de performatividade de gênero. Navarro, que estudou com cuidado a teoria da performatividade de gênero em Butler, também descata que, em Cuerpos que importan, ela faz um esforço de distinguir

entre um modelo de gênero limitado à noção de performance e outro que se desenvolve nos termos previstos na teoria da performatividade de gênero. A distinção é importante posto que, onde a paródia implica um modelo voluntarista, fundamentalmente teatral, da representação genérica, a performatividade recorre a uma ampla - e variada - tradição textual e filosófica que desafia, entre outras pretensões teóricas, o ilusório controle 
intencional pleno das citações da norma em virtude das quais se constitui o sujeito. Podemos assinalar, em consequência, não só - com Butler - a performance como um aspecto ou momento da performatividade (e não como seu limite), mas, também a paródia como momento de resignificação e, em consequência, da política (e não como seu limite) (Navarro, 2012:32).

Nas suas produções mais recentes, embora aparente estar preocupada com outras questões, Butler continua o esforço de pensar, ampliar e qualificar a sua teoria da performatividade. Nem sempre ela está pensando especificamente em gênero, mas em questões mais amplas que envolvem a performatividade da política (ver, por exemplo, Butler, 2015). Mas isso não quer dizer que ela ainda não esteja pensando especificamente na sua teoria da performatividade de gênero. Em conferência realizada em 2014, em Madri, ela voltou a responder aos seus críticos ao destacar que nunca pensou que as nossas performatividades de gênero fossem totalmente espontâneas ou engessadas e determinadas pelas normas. Vejamos como ela explicou essas questões:

A formulação "o gênero é performativo" se converteu na base de muitas e longas discussões sobre temas que incluíam duas interpretações bastante opostas: a primeira era de que elegemos radicalmente nossos gêneros; a segunda, que estamos absolutamente determinados pelas normas de gênero. Essas respostas totalmente divergentes significam que algo não foi bem articulado o bastante $e$ captado no que diz respeito às dimensões duais de qualquer descrição da performatividade. Pois se a linguagem atua sobre nós antes de que atuemos e continua atuando no mesmo momento em que atuamos, temos que pensar a performatividade de gênero primeiro como uma "assignação de gênero": todos esses modos com os quais nos nomeiam e nos nomearam, que nos atribuem um gênero antes de que entendamos nada sobre como as normas de gênero atuam sobre nós e nos conformam, $e$ antes de nossa capacidade para reproduzir essas normas de 
modo que possamos eleger. A eleição, de fato, chega mais tarde nesse processo de performatividade. $\mathrm{E}$, em segundo lugar, seguindo Sedwigck, temos que entender como as desviações a respeito dessas normas podem ter lugar, e o têm, de fato, sugerindo que algo "queer" opera no coração da performatividade de gênero, uma raridade que não é muito distinta das voltas que toma a iterabilidade na explicação de Derrida sobre o ato de fala como citacional.

Assim que vamos assumir, pois, que a performatividade descreve tanto os processos de sermos representados como as condições e possibilidades para atuar, e que não podemos entender essa operação sem ambas as dimensões. As normas que atuam sobre nós implicam que somos suscetíveis à sua ação, vulneráveis a certos nomes desde o princípio. E isso se registra em um nível que é anterior a qualquer possibilidade de vontade. A compreensão da assignação de gênero há de afrontar esse campo de receptividade involuntária, suscetibilidade $e$ vulnerabilidade, um modo de ser expostos à linguagem antes de qualquer possibilidade de formar ou formular um ato discursivo. Normas como essas requerem $e$ instituem certas formas de vulnerabilidade corporal sem as quais sua operação não seria pensável. É por isso que podemos - e de fato o fazemos - descrever a poderosa força citacional das normas de gênero quando são instituídas e aplicadas por instituições médicas, legais e psiquiátricas e objetar sobre o efeito que possuem na formação da compreensão de gênero em termos patológicos ou criminais. Ainda assim, esse mesmo domínio da suscetibilidade, a condição de ser afetado, é também o lugar onde algo estranho pode acontecer, onde a norma é rechaçada ou revisada, ou onde começam novas formulações de gênero.

Ainda que as normas de gênero nos precedem e atuam sobre nós (esse é um sentido de sua colocação em cena), estamos obrigados a reproduzi-las (e esse é o segundo sentido de sua colocação em cena). Precisamente porque algo involuntário $e$ inesperado pode ocorrer neste reino em que "somos afetados", encontramos formas de gênero que rompem 
com os padrões mecânicos de repetição, desviando-se, ressignificando $e$, às vezes, rompendo bastante enfaticamente essas cadeias citacionais da normatividade, dando origem a novas formas de gênero. A teoria da performatividade de gênero, como eu a entendia, nunca prescreveu quais performances de gênero eram corretas, ou mais subversivas, e quais eram incorretas e reacionárias. A questão era precisamente relaxar a pressão coercitiva das normas de gênero sobre a vida - que não é o mesmo que transcender todas as normas - com a finalidade de viver uma vida mais vivível (Butler, 2014:7, grifos nossos).

\section{Perfechatividades - performance, fechação ${ }^{4}$ e performatividade}

Optamos por reproduzir essa longa citação para frisar dois aspectos: mesmo depois de 29 anos de sua primeira publicação, Butler ainda sente necessidade de negar que sua teoria da performatividade pense o gênero de forma voluntarista. $\mathrm{O}$ segundo aspecto é para destacar que, em vários textos, como o citado acima, Butler também usa, às vezes, as palavras performatividade e performance como sinônimas, vide nosso grifo em itálico. Isso se tornou muito comum em vários estudos que utilizam a teoria da performatividade de gênero. $E$ isso não quer necessariamente dizer que as pessoas, ao usarem a ideia de performance, estejam pensando apenas em performances artísticas. A própria popularização da palavra performance, inicialmente mais ligada às artes, acabou por significar muitas coisas e hoje não é difícil alguém dizer que tal pessoa tem uma boa performance no sexo, ou no trabalho, nos estudos etc. ${ }^{5}$

4 Obviamente não pretendemos dar a entender que a fechação é uma novidade na vida de pessoas gays. Nem o uso da palavra é uma novidade. Como nos diz Edward MacRae (2011:28), que analisou as tensões políticas existentes nos primeiros grupos homossexuais do Brasil, já em 1980, em um protesto contra a repressão policial em São Paulo, em que um dos slogans mais repetidos era: "Agora, já, queremos é fechar".

5 A palavra performance já consta no dicionário Aurélio de Língua Portuguesa, que aponta esse duplo significado: para descrever práticas artísticas e para se referir a desempenho ótimo, alcançar, executar algo etc. 
Se recorrermos aos estudos da performance no campo das artes, o uso polissêmico da ideia de performance e até a distinção entre ela $e$ a performatividade ficam ainda mais complicadas. Renato Cohen (2002), no livro $A$ performance como linguagem, demonstra como é difícil definir o que é a performance dentro ou fora do campo das artes.

De uma forma cronológica, podemos associar o início da performance com o século XX e o advento da modernidade.
A rigor, antropologicamente falando, pode-se conjugar o nascimento da performance ao próprio ato do homem se fazer apresentar (a performance é uma arte cênica) e isso se dá pela institucionalização do código cultural (Cohen, 2002:3).

Ainda que o trabalho de Cohen ofereça uma rica reflexão sobre características gerais da performance artística, ele é rígido em pensar a relação entre performer e a performance.
E é importante clarificar-se essa noção; quando um performer está em cena, ele está compondo algo, ele está trabalhando sobre sua "máscara ritual" que é diferente da sua pessoa do dia a dia. Nesse sentido, não é lícito falar que o performer é aquele que "faz a si mesmo" em detrimento do representar a personagem. De fato, existe uma ruptura com a representação, como demonstramos no capítulo seguinte, mas este "fazer a si mesmo" poderia ser melhor conceituado por representar algo (no sentidol de "simbolizar" em cima de si mesmo (Cohen, 2002:58).

No entanto, se acionarmos trabalhos mais recentes sobre o tema, a ruptura com a representação vai ser pensada de forma mais radical e não existirá mais a necessidade de diferenciar o artista da sua performance. Isso fica bem explícito no chamado teatro performativo, que sofreu impactos do campo da performance e da discussão teórica da performatividade, de Austin e Butler inclusive, como demonstra a tese de doutorado de Daiane 
Dordete Steckert (2015). Recorrendo a Josette Féral (2008), que cunhou a expressão Teatro Performativo para se referir à centralidade da performatividade no teatro contemporâneo, Steckert diz que "a influência da arte da performance no teatro transforma atrizes $e$ atores em criadorxs $e$ executorxs de suas ações".

O processo performativo age diretamente no coração $e$ no corpo da identidade do performer, destruindo, reconstruindo seu eu, sua subjetividade, sem a passagem obrigatória por uma personagem. A performance toca $\mathrm{o}$ sujeito que vai para a cena, que se produz, que executa. Se o ator performa, ele realmente age com o seu corpo e sua voz em cena (Féral, 2008:83, apud Steckert, 2015:134).

As reflexões de Steckert (2015) sobre a performance e o teatro performativo nos permitem concluir que essas práticas artísticas, que rompem com certas formas canônicas de produzir arte, hoje não podem ser pensadas de uma forma distinta da performatividade de gênero do artista. Isso porque uma das caraterísticas fortes da performance é a implicação intensa do artista naquilo que está sendo performado. ${ }^{6}$ Como nos mostra Janaina Fontes Leite (2017), essa discussão, emergente nos estudos das artes no Brasil, tem sido abordada de várias maneiras, através, por exemplo, do conceito de "teatro do real", "teatro documentário" ou o que ela propõe como "auto escrituras performativas". Se pensarmos em uma certa cena artística atual do Brasil, que em outro lugar nomeamos de artivismos das dissidências sexuais e de gênero (Colling, 2017), perceberemos nitidamente que não é possível diferenciar a performance artística

\footnotetext{
6 Nesse sentido concordamos com Preciado que, em texto de 2005, apenas em uma nota de rodapé, já apontava para essa direção ao dizer que "o risco de utilizar a noção de "performance" para definir o gênero é que essa noção poderia reafirmar a distinção ontológica clássica entre a cena teatral e a cena anatômica" (Preciado, 2005:128). No entanto, a crítica de Preciado a Butler, como vimos, não se fundamenta nisso, mas na questão da materialidade do corpo e no aspecto voluntarista que o gênero teria na teoria da performatividade.
} 
da performatividade de gênero de boa parte dessas pessoas artistas. $^{7}$

Ou seja, nesse sentido, o problema não está em usar performance e performatividade como sinônimos, mas em pensar em outras questões que possuem relação com os grifos em negrito que apontamos na longa citação de Butler e que têm o objetivo de fazer uma outra provocação: por que não pensamos em uma profusão de conceitos para nomear essas outras performatividades de gênero que rompem com a cadeia de citacionalidade esperada pela normatividade? Como nomear esse algo de "queer que opera no coração da performatividade de gênero"? Bastaria chamar essas performatividades por performatividades queer? Pensamos que não. ${ }^{8}$

As pessoas trans que produziram trabalhos mais recentes se apropriaram do conceito de cisgeneridade para nomear a norma. Nesses estudos, por oposição às pessoas cisgêneras, existem as pessoas trans (travestis, transexuais). ${ }^{9}$ Como Colling (2015) já

7 Pensamos, por exemplo, em como seria difícil diferenciar a performance artística de artistas como Linn da Quedrada ou Miro Spinelli de suas performatividades de gênero. Nesses casos é a própria performatividade de gênero que é a expressão artística ou que, pelo menos, move e tematiza as produções artísticas dessas pessoas. Pretendemos desenvolver esse tema em textos futuros.

8 Tiago Duque (2017) também tem colaborado nesse sentido e, para pensar nas experiências por passar ou não por homem e mulher, vivenciadas, em sua maioria, por pessoas trans, recuperou uma frase de Butler e cunhou o conceito de "gêneros incríveis".

9 O conceito de cisgênero varia a depender de quem o utiliza. Em texto postado no blog Transfeminismo, Bia Pagliarini Bagagli conceitua cisgênero da seguinte forma: "[...] uma explicação simples é que se você se identifica como o gênero que lhe foi designado em seu nascimento, você é cis" [http://transfeminismo.com/o-que-e-cisgenero/ - acesso em: 10 jan. 2015]. Hailey Kaas, outra importante ativista transfeminista brasileira, diz: "O alinhamento cis envolve um sentimento interno de congruência entre seu corpo (morfologia) e seu gênero, dentro de uma lógica onde o conjunto de performances é percebido como coerente. Em suma, é a pessoa que foi designada 'homem' ou 'mulher', se sente bem com isso e é percebida e tratada socialmente (medicamente, juridicamente, politicamente) como tal" 
destacou em outro texto, o conceito de cisgeneridade gerou impactos importantes nas discussões mais recentes sobre sexualidade $e$ identidade de gênero. No entanto, naquele texto, Colling perguntou:

Um gay afeminado, por exemplo, que não performa o seu gênero da maneira como exige a norma, é trans ou

[https://ensaiosdegenero.wordpress.com/2012/09/17/o-que-sao-pessoas-cis-ecissexismo/ - acesso em: 10 jan. 2015]. Jaqueline Gomes de Jesus (2014) diz que "[...] cisgênero é um conceito que abarca as pessoas que se identificam como o gênero que lhes foi determinado socialmente, ou seja, as pessoas nãotransgênero [...]". No texto O cisgênero existe, publicado no site Transliteração [http://transliteracao.com.br/leiladumaresq/2014/12/o-cisgenero-existe/ - acesso em: 10 jan. 2015], é possível encontrar definições parecidas: "A definição mais antiga de 'cisgênero' que encontrei é esta: 'Uma vez que definimos gênero como 'as características comportamentais, culturais ou psicológicas associadas a um sexo, cisgênero literalmente significa: estar do mesmo lado das características comportamentais, culturais ou psicológicas associadas a um sexo. Simplificando, significa que a identidade e a apresentação de alguém são compatíveis com sua morfologia física"'. O texto também cita Julia Serano, que define cisgênero assim: "Como alguém que foi designada masculina ao nascer, mas que vive e identificase como feminina, eu devo ser descrita como uma mulher transexual, mulher transgênera ou mulher trans. Aquelas mulheres que (diferentes de mim) foram designadas femininas ao nascer, devem ser descritas como mulheres cissexuais, mulheres cisgêneras ou mulheres cis". Ainda no mesmo texto, Viviane Vergueiro define: "Cisgeneridade eu entendo como um conceito analítico que eu posso utilizar assim como se usa heterossexualidade para as orientações sexuais, ou como branquitude para questões raciais. Penso a cisgeneridade como um posicionamento, uma perspectiva subjetiva que é tida como natural, como essencial, como padrão. A nomeação desse padrão, desses gêneros vistos como naturais, cisgêneros, pode significar uma virada descolonial no pensamento sobre identidades de gênero, ou seja, nomear cisgeneridade ou nomear homens-cis, mulheres-cis em oposição a outros termos usados anteriormente como mulher biológica, homem de verdade, homem normal, homem nascido homem, mulher nascida mulher, etc. Ou seja, esse uso do termo cisgeneridade, cis, pode permitir que a gente olhe de outra forma, que a gente desloque esse posição naturalizada da sua hierarquia superiorizada, hierarquia posta nesse patamar superior em relação com as identidades Trans, por exemplo". O texto do site Transliteração foi uma resposta ao texto de Carla Rodrigues, intitulado $O$ cisgênero não existe [http://www.blogdoims.com.br/ims/o-cisgenero-nao-existe - acesso em: 10 jan. 2015]. 
cisgênero? Podemos dizer, em termos absolutos, que alguém consegue perfeitamente "estar do mesmo lado das características comportamentais, culturais ou psicológicas associadas a um sexo"? Quantas pessoas vacilam nessa tentativa de seguir a norma para estar desse "mesmo lado"? (Colling, 2015:61).

Colling sugeriu que as pessoas pesquisadoras do campo da sexualidade e gênero, ao invés de ignorar ou defender que o cisgênero não existe $e^{10}$, deveriam colaborar conceitualmente com o debate sobre cisgeneridade versus transgeneridade. ${ }^{11}$ Foi pensando nisso que Colling provocou dois pesquisadores de Salvador que produziram trabalhos sobre gays afeminados. Dessas provocações surgiu a ideia de escrever este texto. Murilo Arruda é autor da tese de doutorado, intitulada $O$ corpo e o gênero fechativo pelas ruas de Salvador. Já Murillo Nonato, defendeu a dissertação de mestrado Problemas de gênero de um gay afeminado.

O trabalho de Arruda consiste em uma ampla etnografia realizada com vários interlocutores que permitiram o autor defender a tese de que existe uma performatividade de gênero que ele nomeia como "fechativa". ${ }^{12}$ Mas essa fechação é um tipo de performatividade de gênero que escapa das normas, aquilo

\footnotetext{
${ }^{10}$ Ver, por exemplo, < $\underline{\text { http://www.blogdoims.com.br/ims/o-cisgenero-nao- }}$ existe >. Acesso em: 16 ago. 2017.

${ }^{11}$ A ativista Hailey Kaas disse: "Não queremos criar uma dicotomia entre pessoas cis e pessoas trans* e sim evidenciar o caráter ilusório da naturalidade da categoria cis" [https://ensaiosdegenero.wordpress.com/2012/09/17/o-que-saopessoas-cis-e-cissexismo/ - acesso em: 10 jan. 2015]. No entanto, a dicotomia acabou por ser instalada, talvez como resultado indesejado. Por outro lado, começa a ser cada vez mais recorrente pensar a cisgeneridade como cistema, como norma que incide sobre todas as pessoas. Isso aparece na crítica ao cistema ou à cisheteronormatividade. Um trabalho precursor nesse sentido é o de Viviane Vergueiro (2015).

${ }^{12} \mathrm{Na}$ primeira versão da tese, o autor usou a categoria de "gênero fechativo" $e$, depois das reflexões realizadas neste texto, a modificou para "performatividade de gênero fechativa".
} 
que Butler chama de "algo queer no coração da perfomatividade" que provoca o inesperado nas regras da citacionalidade? Ou seria uma performance de gênero intencional utilizada apenas em determinados contextos, locais e com determinadas pessoas, o que, nesses casos, nos termos de Butler, não poderia ser chamada de performatividade de gênero e nem de gênero, pois nela existe um sujeito por trás do ato e que age deliberadamente em um determinado intervalo de tempo e condições?

Nos elementos da tese de Arruda e da dissertação de Nonato, se forem lidos com cuidado, veremos que os gays afeminados $e$ fechativos nos ensinam muito mais do que a oposição entre performance e performatividade. Essas gays (assim no feminino, como muitas delas se auto-identificam) também borram a fronteira entre performatividade e performance de gênero, fronteira essa que, paradoxalmente, como vimos, foi pensada por Butler de forma rígida, talvez pela necessidade de responder aos seus críticos. O que os campos de Arruda (2017) e de Nonato (2017) deixam evidente é que a fechação e/ou a performance afeminada é realizada com muito mais intensidade em determinados contextos e locais $e$ a depender da situação $e$ dos interesses envolvidos. No entanto, mesmo que queiram, as fechativas e/ou as afeminadas, quando diminuem a intensidade de suas fechações e o seu afeminamento, também operam pela lógica da performance pontual, em especial quando estão em situações de risco ou ocasióes em que sabem que podem ser rechaçadas. Vejamos um trecho da tese de Arruda, quando ele relata algumas experiências de Ariel, um de seus interlocutores:

Conversar sobre os acontecimentos da vida de Ariel "dentro de casa" é sinônimo de tornar as situações vividas por ele difusas, desespacializadas e descontextualizadas dos trânsitos e encontros fora de casa, evitando assim qualquer referência ao seu corpo/gênero.

Quando a gente [o pai, a mãe e o irmão] se senta para meu pai preparar a carne, eu me faço de morta. [...] É muito 
bom, principalmente a comida, mas eu fico duro, pareço até meu irmão. (Ariel)

Minha mãe sabe que eu vou para casa de Milene, sabe quem ela é, que a mãe dela gosta muito de mim, mas não sabe o que a gente apronta.

Isso eu não digo. Imagine minha mãe saber que na casa de minha tia, a gente fica testando maquiagem? Tá louca?! Acho que minha mãe surtaria... ela nem ia dizer nada, mas ia ficar em choque... acho que ia chorar um mês sem parar (risos). (Ariel)

Com isso, Ariel explica como transcorrem os encontros familiares, especialmente quando o pai prepara sua receita especial: ele silencia sua expressividade corporal e evita falar de situações, como as vividas com Milene cheias de fechações. Seu corpo é enquadrado pelo mero estar diante dos familiares, que remonta aos poderes geracionais, atravessados por hegemonias de gênero. A reunião dos familiares sentados ao redor da mesa, enquanto o pai prepara a carne, atualiza o poder geracional e gendrado dos pais, definindo a pauta de conversa e demandando ajuste entre gestual de Ariel e sua maneira de se comportar à mesa; trata-se de uma verdadeira negociação através de um jogo entre os corpos expressivos habituados à rotina dos comportamentos no dia a dia da família.

Ariel, ao dizer que "endurece" ao entrar em casa, fala deste custo para existir na e com sua família, mediante institucionalização de movimentos, pautas e trânsitos pelos espaços da casa. A maneira de estar em casa, adequada ao que se apreendeu ao longo dos anos, produz um efeito no comportamento de Ariel que coexiste com todo o investimento de fabricação do seu corpo, pela rua e na casa de Milene. Endurecer, se é uma maneira de ocultar seu corpo, suas experiências e desejos, é também uma maneira de poder acessar o amor e a afeição de seus pais (Arruda, 2017:148). 
O trabalho de Murillo Nonato (2017) também analisa um interlocutor chamado pelo pesquisador por Arie $\mathrm{l}^{13}$ que negocia, a depender dos espaços que frequenta, entre o seu lado afeminado e seu lado "durinho", que agora aparece na expressão "não dar pinta". Eis como Nonato (2017) analisa o caso:

Em seu relato, Ariel aponta que a dissimulação da feminilidade do seu corpo e do seu comportamento se configuram como uma estratégia para escapar das possíveis punições cabíveis ao corpo afeminadx em uma sociedade cisheteronormativa. A necessidade de moldar o corpo e o comportamento ou de "ficar quieto para não dar pinta" aparece com frequência nas narrativas dxs afeminadxs e se configura como uma tentativa de negociar com esse espaço que os rodeia, nesse caso, especificamente, o ambiente familiar, como apontou Eribon. Essa dissimulação surge como um recurso para driblar as surras e as chantagens. As chantagens, especialmente, revelam que a identificação da feminilidade nos revela a vulnerabilidade social do sujeito que é gênero inconforme e, de certa forma, também revela certa autoridade e poder sobre xs afeminadxs ao passo em que aponta o seu lugar no mundo, o da abjeção (Nonato, 2017:s/p).

$\mathrm{O}$ que esses trechos nos permitem dizer em relação ao que estamos sugerindo aqui neste texto? As gays afeminadas permanecem num trânsito constante entre o ato da fechação, que implica em ficar molinho, fazer determinados gestuais e usar determinado vocabulário, que Carlos Henrique Lucas Lima (2016) também analisou através do pajubá das "pajubeyras", e o ficar durinho, que implica em fazer o possível para deixar o afeminamento e a fechação de lado. No entanto, esses dois momentos, digamos assim, não possuem uma fronteira totalmente delimitada. Por mais que o gay fechativo endureça voluntariamente em determinados momentos, traços ligados à

${ }^{13}$ Os pesquisadores informam que usaram o mesmo pseudônimo para duas pessoas diferentes. 
fechação que nutrem suas expressões corporais como resultado de repetições performativas nunca desaparecem por completo. E vice-versa, pois na fechação, em alguns momentos, o gay durinho também ganha mais força.

Grosso modo, as gays afeminadas, quando investem intencionalmente em um exercício performático para aparecer diante do outro mais "durinha", não controlam completamente os efeitos que a performatividade amalgamou na materialidade expressiva de seu corpo. Na mesma direção, quando performam a fechação, acentuando sua expressividade afeminada, encenam trejeitos, movimentos e tons de voz que garantem que elas sejam vistas como gays fechativas. Dessa forma, performar a fechação corresponde a um instante intencional de fazer seu corpo contar, diante do outro, como fechativa. Do mesmo modo, quando pretendem endurecer, só parte dos movimentos expressivos do afeminado são acentuados, o que aponta para uma dimensão perene e impossível de controlar dos efeitos performáticos que estão na materialidade de seus corpos.

Arruda (2017) também demonstrou como há uma dimensão voluntária durante o caminhar de gays fechativas pelas ruas da cidade. Em diversos momentos do campo, as personagens demonstram ou narram o receio de caminhar por entre os demais transeuntes sem que seu corpo/gênero fechativo não seja percebido como tal. Ao caminhar entre a escola onde estuda e a praça do Campo Grande, como é conhecida a Praça 2 de Julho, em Salvador, Ariel, trajando a camisa da farda escolar, tamanho "PP", acentuava a languidez expressiva de seu corpo para garantir que os efeitos performativos que o materializavam seriam o eixo da percepção dos outros sobre ele. Ao chegar na praça, próxima à sua escola, Ariel entregava-se aos gracejos entre amigos e seu corpo, sem preocupações voluntárias, seguia com sua expressividade fechativa, nutrido dos efeitos performativos de suas repetições cotidianas de gênero.

Ainda em referência ao caminhar de Ariel entre a escola e a praça do Campo Grande, Arruda destaca que ele vestia uma calça skinny comprada na seção de roupas femininas de uma loja de 
departamento. Ao contrário da farda escolar que obedece à padronização da Secretaria de Educação do Estado da Bahia, a calça havia sido cuidadosamente escolhida na seção feminina de uma loja de departamento. A escolha da calça foi cuidadosamente pensada por Ariel para, ao mesmo tempo, acentuar sua expressividade corporal e suavizar os feitos do fardamento padronizado. Agenciar o movimento expressivo de seu corpo/gênero, por outro lado, era uma estratégia de Ariel para mitigar o sentido de feminino que o estilo da calça continha. "O corpo [expressivo] 'escondia' o estilo feminino, e a calça 'escondia' o que, ao olho do outro, seria um corpo masculino" (Arruda, 2017:113).

Eu não tenho meu dinheiro ainda: compro roupa com o dinheiro do meu pai que jura que eu sou homem. Mas quando eu vou ao shopping, compro roupa na parte de menina, porque fica bem no meu corpo e ninguém sabe que estou usando roupa de menina. [...] Mas teve um dia que uma menina me disse na lata: essa calça é de mulher. Eu respondi: "Não, meu amoooorrrr... essa calça é de meninnnaaa... [solta um sonoro beijo]. Deixe de ser "Alice"! ${ }^{14}$ (Ariel).

A questão para Ariel não era propriamente "esconder" o sentido feminino da calça ou "esconder" o que o olhar do outro compreende como masculino. Ao contrário: Ariel queria garantir que o olhar do outro, em espaços públicos (Goffman, 2010 e 2011), iria fixar que este matiz de expressividade fosse caminhando pelas ruas e/ou em outros lugares de sociabilidade. Ariel faz uso de roupas que provoquem uma ambivalência compreensiva entre seu corpo e o outro, cujo olhar vai em busca de um sentido "normal"/moral para iniciar uma interação. A calça que não era de menina, mas de "meninnnaaaa" (com o desfecho de um beijinho lançado no ar, um ponto final fechativo),

14 "Ser Alice" é uma expressão que designa uma atitude, ideia, opinião ou receio ingênuo, pueril. 
perdia seus sentidos substantivos para lhe servir de mediador e agente possibilitador da realização do desejo de consumo de Ariel. A calça havia sido fabricada visando a um público que não Ariel e tantas outras pessoas. Ariel, que não está mais rendido por princípios binários que o levam a conviver com amigos, familiares e em diversos lugares, também não consome suas roupas como refém dos sentidos binários das prateleiras. Ele não usa uma calça feminina, mas uma qualidade de vestuário no horizonte de seu tipo físico e o efeito que vislumbra no outro, quando de sua passagem ou em situações de interação. O conjunto entre corpo, calça, adereços e expectativa de comportamento do outro mostra como Ariel dessubstancializa os sentidos de masculino que sua família lhe atribuiu, e os sentidos de feminino que o mercado substancializa no vestuário, espaços comerciais e nos seus trabalhadores. A calça passa, assim, a ser uma peça fechativa, para um corpo/gênero fechativo (Arruda, 2017:113).

A pesquisa de Nonato (2017) também aponta para esses momentos em que as pessoas interlocutoras borram as fronteiras entre performance e performatividade de gênero. Ao entrevistar Andreas, de 21 anos, estudante de história pela Universidade Federal da Bahia (UFBA), residente no bairro Patamares, negrx, de estatura baixa e magrx, Andreas vestia calças e blusas tipicamente masculinas. A masculinidade aparente ia se desmontando e se ressignificando na medida em que o corpo ganhava movimento e expressividade. Os gestos espalhafatosos e a voz aguda ressoavam pelo recinto e produziam novas leituras e sentidos sobre aquele corpo afeminadx.

Nonato (2017) narra que Andreas chegou ao local do primeiro encontro uma hora atrasado, apressado, pedindo desculpas e culpando o complicado trânsito de final de tarde em Salvador. Antes mesmo de terminar seu pedido de desculpas, avistou um amigx e, de repente, se levantou. Ambos pararam a alguns metros de distância um do outro por alguns segundos para, logo depois, iniciarem um ritual quase que teatral em que 
reproduziam expressões de dor; alegria; medo; rodopiavam $e$ dançavam para finalizar se abraçando com uma interpelação: "vinhaaadooo"!

Nos nossos primeiros diálogos, ainda tímidos, tateávamos a experiência daquele encontro, mas rapidamente pude perceber que enquanto Andreas se expressava ao se comunicar oralmente construindo suas narrativas de vida, seu corpo se expressava junto completando seus discursos. As mãos dançavam no ar freneticamente, o tronco se remexia acompanhado a fala e a cabeça acompanhava a dança do resto do corpo. Nos nossos primeiros encontros compreendi que aquele corpo falava, e falava "afeminadamente", daquele corpo emanava um discurso em oposição aos ditames da cisheteronormatividade, aqueles corpos que "afeminadamente" se comunicavam também eram alvo de violências, punições e tentativas de controle, mas também de resistências (Nonato, 2017, p. 83).

Andreas também ofereceu para Nonato (2017) outra explicação sobre a necessidade de, em alguns momentos, deixar um pouco a fechação de lado.

Essa é a pior parte de se enxergar tendo trejeitos, de estar confortável como a sua identidade e tal. É... eu não tinha a ideia de que havia essa segregação. A gente começa a tomar na cara e vê. Poxa! Então teve uma época que para ser aceito, então para dar uns pegas na balada eu não dançava, quando eu queria pegar alguém eu não dançava. Fazia aquela dancinha, sabe? Um pé para o lado e um pé para o outro, mas eu não dançava do jeito que eu gostava de fazer coreografia, de dançar. Hoje em dia eu não ligo mais para nada, sabe? Hoje eu posso morrer solteira, mas não perco meu close para nada. Mas tipo, foi um processo que eu comecei a fazer e... Os trejeitos eu controlava, eram poucos, eu me controlava na escola, para mim era tranquilo. Mas, tipo, eu tinha que omitir que eu queria ir para a balada usando salto, lápis de olho, delineador, pó, base, roupa curta, sabe? Porque até então o que tinha na 
minha cabeça é que isso não era atrativo, as pessoas não vão querer ficar comigo, então não vou ser assim, vou ser como todo mundo quer que eu seja. Hoje eu só me relaciono com pessoas que aceitem meu close, meu batom na boca. Não vou dizer que isso não me afeta, às vezes eu paro e penso e fico "putzzz, ahhhh" e chega um cara tão bonitinho, mas ele não chegaria num rapaz assim, realmente, e eu fico triste com isso, mas não penso em parar de ser como eu sou como eu pensava antigamente (Nonato, 2017:s/p.).

Por questões levantadas nessas pesquisas, sugerimos pensar essas expressões de gênero de gays afeminados fechativos (ou das gays afeminadas fechativas) como perfechatividades de gênero, o que aglutinaria uma combinação entre fechação e performance, ainda naquele sentido de que por vezes é realizada de forma bem mais intencional, e performatividade, quando a intencionalidade diminui $e$ a repetição torna-se mais naturalizada, mas que, no sentido antropológico de Cohen (2002), não deixa de ser também uma performance. O que evidenciamos é que tanto na performance quanto na performatividade entram em cena as matrizes de gênero que não deixam de operar, ainda que seja para serem subvertidas ou borradas. São essas matrizes que acabam por constituir os próprios sujeitos, como diz Butler.

Ao propor a noção de perfechatividade, ao invés de justapor os termos performance e performatividade, borrando as fronteiras entre dois conceitos, preferimos injetar a noção de fechação no núcleo da performatividade. Dessa forma, a perfechatividade pretende superar os limites conceituais de uma terminologia que não auxilia a compreender a experiência das bichas afeminadas e fechativas que, como vimos, em situações limites, apropriam-se voluntariamente de seus movimentos corporais, acentuando ou diluindo expressividades anexadas pelo transcurso temporal $e$ espacial de repetições performativas de gênero. Talvez essa seja a razão principal de propormos a noção de perfechatividade e não somente fechação. A fechação pura e simples remete a uma ação voluntária momentânea, que tem o intuito de "causar", de 
"lacrar", de exagerar. Já a performatividade de gênero, como vimos, tem como princípio a repetição, ou melhor, a persistência de uma repetição que, ao final, se naturaliza nos corpos. A perfechatividade quer olhar para o que fica entre esses dois extremos: a fechação que existe na performatividade e a performatividade que existe na fechação.

Essas perfechatividades, como bem demonstram os trabalhos de Arruda (2017), Lima (2016) e Nonato (2017), são bem distintas entre si e, por isso, o uso do plural também se faz necessário. Longe de ser proposta como uma categoria identitária, as perfechatividades teriam a vantagem de abrir espaço para a discussão em torno da diversidade existente entre as inúmeras performatividades de gênero que existem em nossa sociedade. Ao invés de focar nas identidades, as perfechatividades focam mais nas performances e performatividades de gênero e abrem o leque para pensarmos em variadas perfechatividades $e$ performatividades, o que nos afastaria de qualquer dualismo ou binarismo, algo que sempre foi muito caro aos estudos queer, independentemente das inúmeras diferenças existentes entre eles.

Além disso, as perfechatividades também podem ser úteis para pensarmos em outra dicotomia que parece estar se consolidando em determinados debates no campo de estudos $e$ políticas da diversidade sexual $e$ de gênero do Brasil da atualidade. Trata-se da dicotomia entre cis versus trans. E aqui não se trata de abandonar ou criticar o conceito de cisgênero, mas de evidenciar que as gays afeminadas e fechativas resistem à heteronormatividade e à cisgeneridade. Ainda que não sejam pessoas que se identifiquem como trans, elas também não são facilmente identificadas como cisgêneras. E quando são identificadas ou se identificam como cisgêneras, elas acabam por evidenciar que existe uma variedade na cisgeneridade. E é sobre essa variedade que talvez valha a pena pensar e propor novos neologismos capazes de nomear e, principalmente, provocar outras reflexões. 


\section{Referências bibliográficas}

ARRUDA, Murilo Souza. O corpo e o gênero fechativo pelas ruas de Salvador. Tese (Doutorado em Ciências Sociais) - Faculdade de Filosofia e Ciências Humanas, Universidade Federal da Bahia, Salvador, 2017

BARAD, Karen. Performatividade pós-humanista: para entender como a matéria chega à matéria. Vazantes, vol. 1, n. 1, 2017, pp.7-34.

BUTLER, Judith. Corpos que pesam: sobre os limites discursivos do "sexo". In: LOURO, Guacira Lopes. O corpo educado: pedagogias da sexualidade. Belo Horizonte, Autêntica, 2001, pp.151-172.

ButLER, Judith. Notes toward a performative theory of assembly. London, Harvand University Press, 2015.

BUTLER, Judith. Repensar la vulnerabilidad y la resistencia. XV Simposio de la Asociación Internacional de Filósofas, Madri, 2014.

BUTLER, Judith. Críticamente subversiva. In: Jiménez, Rafael M. Mérida. Sexualidades transgresoras. Una antología de estúdios queer. Barcelona, Icária editorial, 2002, pp.55-80.

ButLen, Judith. Problemas de gênero. Feminismo e subversão da identidade. Rio de Janeiro, Civilização Brasileira, 2003.

BuTLER, Judith. Prefácio. In: El género en disputa. El feminismo y la subversión de la identidade. Barcelona, Paidós, 2007, pp.7-33. [1999]

BUTLER, Judith. Cuerpos que importan. Sobre los limites materiales y discursivos del "sexo". Buenos Aires, Paidós, 2008.

BuTLER, Judith. Meramente cultural. Idéias, Campinas, São Paulo, vol. 7 , n. 2, jul/dez 2016, pp.227-248.

CHAZAN, LK. "Meio quilo de gente": um estudo antropológico sobre o ultra-som obstétrico. Rio de Janeiro, Editora Fiocruz, 2007.

CoHEn, Renato. Performance como linguagem. Criação de um tempoespaço de experimentação. São Paulo, Editora Perspectiva, 2002.

COLLING, Leandro. Que os outros sejam o normal: tensões entre movimento LGBT e ativismo queer. Salvador, EDUFBA, 2015. 
COLLING, Leandro. Artivismos das dissidências sexuais e de gênero. Revista CULT, n. 226, agosto de 2017.

CYFER, Ingrid. Afinal, o que é uma mulher? Simone de Beauvoir e "a questão do sujeito" na teoria crítica feminista. Lua Nova, n.94, São Paulo, 2015, pp.41-77.

DUQUE, Tiago. Gêneros incríveis: um estudo sócio-antropológico sobre as experiências de (não) passar por homem elou mulher. Campo Grande, Editora da UFMS, 2017.

FEMENÍAs, María Luisa. Judith Butler: introducción a su lectura. Buenos Aires, Catálogos, 2003.

FÉRAL, Josette. Por uma poética da performatividade: o teatro performativo. Sala Preta, vol. 8, 2008, pp.197-210.

FRASER, Nancy. Heterossexismo, falso reconhecimento e capitalismo: uma resposta a Judith Butler. Idéias, Campinas, São Paulo, vol. 8, n. 1, jan/jun 2017, pp.277-294.

LEITE, Janaina Fontes. Autoescrituras performativas. São Paulo, Perspectiva, 2017.

LiMA, Carlos Henrique Lucas. Linguagens pajubeyras: re(ex)sistência cultural e subversão da heteronormatividade. Tese (Doutorado em Cultura e Sociedade) - Instituto de Humanidades, Artes e Ciências Professor Milton Santos, Universidade Federal da Bahia, Salvador, 2016.

MACRAE, Edward. Os respeitáveis militantes e as bichas loucas. In: ColliNG, Leandro (org.). Stonewall $40+$ o que no Brasil? Salvador, EDUFBA, 2011, pp.21-36.

NAVARRo, Pablo Pérez. Del texto ao sexo - Judith Butler y la performatividad. Editorial Egales, Barcelona/Madrid, 2008.

NAvarro, Pablo Pérez. Parodias de la parodia en Martha Nussbaum y Celia Amorós. In: SOley-Beltran, Patrícia; SABSAY, Leticia. Judith Butler en disputa - lecturas sobre la performatividad. Barcelona, Madrid, Egales, 2012, pp.27-58.

NONATO, Murillo. Problemas de gênero de um gay afeminado. Dissertação (Mestrado em Cultura e Sociedade) - Instituto de 
Humanidades, Artes e Ciências Professor Milton Santos, Universidade Federal da Bahia, Salvador, 2017.

PRINS, Baukje; MEIJER, Irene Costera. Como os corpos se tornam matéria: entrevista com Judith Butler. Rev. Estud. Fem. [online]. 2002, vol.10, n.1, pp.155-167.

SALIH, Sara. Judith Butler e a teoria queer. Belo Horizonte, Autêntica, 2012.

PRECIADO, Paul B. Manifiesto contra-sexual. Madrid, Opera Prima, 2002.

PRECIADO, Paul B. Cuerpo y discurso em en la obra de Judith Butler: políticas de lo abyecto. In: CóRDOBA, David; SÁEZ, Javier; VIDARTE, Paco P. (org.). Teoria queer: políticas bolleras, maricas, trans, mestizas. Madrid, Editorial Egales, $2^{a}$ edición, 2005, pp.111-132.

PRECIADO, Paul B. Testo yonqui. Madrid, Editorial Espasa Calpe, 2008.

STECKERT, Daiane Dordete. Possível cartografia para um corpo vocal queer em performance. Tese (Doutorado em Teatro) - Centro de Artes, Universidade do Estado de Santa Catarina, Florianópolis, 2015.

Vergueiro, Viviane. Por inflexóes decoloniais de corpos e identidades de gênero inconformes: uma análise autoetnográfica da cisgeneridade como normatividade. Dissertação (Mestrado em Cultura e Sociedade), Instituto de Humanidades, Artes e Ciências Professor Milton Santos, Universidade Federal da Bahia, Salvador, 2015. 